\title{
Effect of S100A8 and S100A9 on expressions of cytokine and skin barrier protein in human keratinocytes
}

\author{
MUN JEONG KIM ${ }^{1}$, MI AE IM ${ }^{2,3}$, JI-SOOK LEE ${ }^{3}$, JI YOUNG MUN ${ }^{1,4}$, \\ DA HYE KIM ${ }^{1}$, AYOUNG GU ${ }^{1}$ and IN SIK KIM ${ }^{1,2}$ \\ ${ }^{1}$ Department of Senior Healthcare, BK21 Plus Program, Graduate School; \\ ${ }^{2}$ Department of Biomedical Laboratory Science, School of Medicine, Eulji University, Daejeon 34824; \\ ${ }^{3}$ Department of Clinical Laboratory Science, Wonkwang Health Science University, Iksan, Jeollabuk 54538; \\ ${ }^{4}$ Department of Biomedical Laboratory Science, College of Health Science, Eulji University, Seongnam, \\ Gyeonggi 13135, Republic of Korea
}

Received May 11, 2017; Accepted June 4, 2019

DOI: $10.3892 / \mathrm{mmr} .2019 .10454$

\begin{abstract}
Atopic dermatitis (AD) is an inflammatory skin disorder caused by immunological dysregulation and genetic factors. Whether the expression levels of cytokine and skin barrier protein were altered by S100 calcium binding protein A8 (S100A8) and S100A9 in human keratinocytic HaCaT cells was examined in the present study. Alterations of cytokine expression were examined by ELISA following treatment with S100A8/9 and various signal protein-specific inhibitors. Activation of the mitogen activated protein kinase (MAPK) pathway and nuclear factor (NF) $-\kappa B$ was evaluated by using western blotting and an NF- $\kappa \mathrm{B}$ activity test, respectively. The expression levels of interleukin (IL)-6, IL-8 and monocyte chemoattractant protein-1 increased following treatment with S100A8 and S100A9, and the increase was significantly blocked by specific signaling pathway inhibitors, including toll-like receptor 4 inhibitor (TLR4i), rottlerin, PD98059, SB203580 and BAY-11-7085. Extracellular signal-regulated kinase (ERK) and p38 MAPK pathways were activated in a time-dependent manner following treatment with S100A8 and S100A9. Phosphorylation of ERK and p38 MAPK were blocked by TLR4i and rottlerin. S100A8 and S100A9 induced translocation of NF- $\mathrm{KB}$ in a time-dependent manner, and the activation of NF- $\mathrm{KB}$ was inhibited by TLR4i, rottlerin, PD98059 and SB203580. In addition, S100A8 and S100A9 decreased the expression of skin barrier proteins, filaggrin and loricrin. These results may help to elucidate the pathogenic mechanisms of $\mathrm{AD}$ and develop clinical strategies for controlling AD.
\end{abstract}

Correspondence to: Dr In Sik Kim, Department of Biomedical Laboratory Science, School of Medicine, Eulji University, 77 Gyeryoung-ro 771 beon-gil, Jung-Gu, Daejeon 34824, Republic of Korea

E-mail: orientree@eulji.ac.kr

Key words: atopic dermatitis, S100 calcium binding protein A8, S100 calcium binding protein A9, keratinocyte, skin barrier protein

\section{Introduction}

Atopic dermatitis (AD) is a chronic inflammatory skin disease. Clinical observations used to diagnose AD include chronic dermatitis, pruritus, facial and extensor eczema in infants and children and flexural eczema in adults (1-3). The prevalence of $\mathrm{AD}$ is increasing annually.

S100A8 and S100A9 are members of the S100 family proteins, having constitutive or inducible expressions in neutrophils and monocytes/macrophages (4). These proteins are included in damage-associated molecular pattern (DAMP), and perform various functions, including control of cell motility, protein phosphorylation for cell activation, and calcium homeostasis for tumor progression or suppression through Toll-like receptor 4 (TLR4) $(4,5)$. High levels of S100 calcium binding protein A8 (S100A8) and S100A9 are characteristic of several inflammatory conditions, such as chronic inflammatory bowel disease, rheumatoid arthritis, cystic fibrosis, psoriasis and $\mathrm{AD}(6,7)$.

Cytokine dysregulation is one of the most important pathogenic mechanisms associated with AD. Interleukin-6 (IL-6), IL-8, and monocyte chemoattractant protein-1 (MCP-1) are essential cytokines involved in the induction and alleviation of $\mathrm{AD}(8)$. In addition, defects in skin barrier function are critical for the development of AD (9). Disruption of skin barrier proteins, including filaggrin, loricrin and involucrin, can make it easier for allergens or antigens to permeate the skin (9). Such defects may be the result of an increase in cytokines or may result in increased production of inflammatory cytokines, including IL-1, IL-2, IL-4, IL-6, IL-8, tumor necrosis factor- $\alpha$ (TNF- $\alpha$ ), and MCP-1. These cytokines and chemokines may both induce and alleviate $\operatorname{AD}(8,9)$.

Based on the above, this study was performed to investigate whether S100A8 and S100A9 are associated with alteration of cytokine secretion and skin barrier proteins.

\section{Materials and methods}

Reagents. TLR4 inhibitor CLI-095 (TLR4i), protein kinase $\delta(\mathrm{PKC} \delta$ ) inhibitor (rottlerin), p38 mitogen-activated 

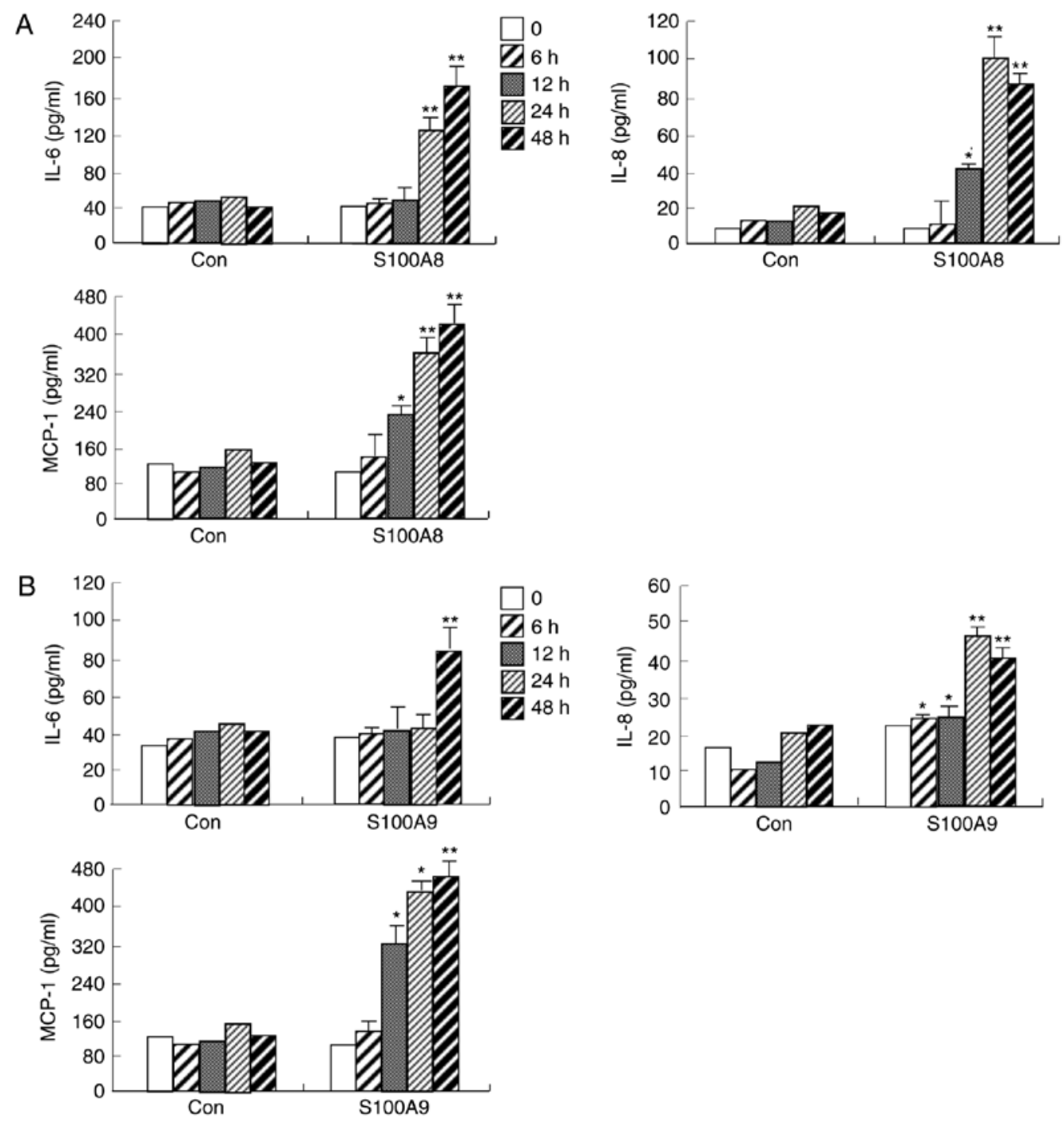

Figure 1. HaCaT cells treated without (Con) or with $10 \mu \mathrm{g} / \mathrm{ml}$ of (A) S100A8 or (B) S100A9 had increased IL-6, IL-8, and MCP-1 production levels in a time-dependent manner, as measured by ELISA. Data are expressed as the mean \pm standard deviation. ${ }^{*} \mathrm{P}<0.05$ and ${ }^{* *} \mathrm{P}<0.01$ vs. Con. S100, calcium binding protein; Con, control; IL, interleukin; MCP, monocyte chemoattractant protein.

protein kinase (MAPK) inhibitor (SB202190), MEK inhibitor (PD98059) and nuclear factor- $\mathrm{KB}(\mathrm{NF}-\mathrm{\kappa B})$ inhibitor (BAY-11-7085) were obtained from Calbiochem (Merck KGaA). Antibodies against p38 MAPK (cat. no. 9212), phospho-p38 MAPK (cat. no. 9211), phospho-extracellular signal regulated kinase 1/2 (ERK1/2; cat. no. 9101), rabbit IgG-HRP (cat. no. 7074), and mouse IgG-HRP (cat. no. 7076) were acquired from Cell Signaling Technology, Inc. Anti-ERK2 (cat. no. sc-154) and anti-TLR4 (cat. no. sc-10741) antibodies were obtained from Santa Cruz Biotechnology, Inc.

Production of recombinant S100A8 and S100A9 proteins. In our previous report, the cDNA of human S100A8 and S100A9 was cloned into pET28 expression vector (Merck KGaA) (10). Recombinant S100A8 and S100A9 expression was induced with $1 \mathrm{mM}$ isopropyl $\beta$-D-thiogalactoside in E. coli BL21 (DE3; Merck KGaA). Subsequently, bacteria were centrifuged at 5,000 x g for $10 \mathrm{~min}$ at $4^{\circ} \mathrm{C}$ and the pellet was lysed in BugBuster Protein Extraction reagent (Merck KGaA). A spectrophotometer (Thermo Fisher Scientific, Inc.) was used for measuring protein concentration in the lysates.
Cell culture. Human keratinocytic HaCaT cells (Addexbio; cat. no. T0020001) were cultured in Dulbecco's modified Eagle's medium supplemented with $10 \%$ heat-inactivated fetal bovine serum (cat. no. 12484-010; Gibco; Thermo Fisher Scientific, Inc.), penicillin (100 U/ml), and streptomycin $(100 \mu \mathrm{g} / \mathrm{ml})$. The cultured cells were maintained at sub-confluency in a $95 \%$ air, $5 \% \mathrm{CO}_{2}$ humidified atmosphere at $37^{\circ} \mathrm{C}$. An Annexin V-fluorescein isothiocyanate (FITC) apoptosis detection kit (BD Biosciences) and an RF500 flow cytometer (Sysmex Corporation) were used to evaluate the cytotoxicity.

ELISA. HaCaT cells were treated with S100A8 or S100A9 for $6,12,24$ and $48 \mathrm{~h}$, followed by centrifugation of the supernatant at $5,000 \mathrm{x} \mathrm{g}$ for $10 \mathrm{~min}$ at $4^{\circ} \mathrm{C}$. The concentrations of IL-6, IL-8 and MCP-1 in the cell supernatant were measured with a sandwich ELISA using OptEIA ${ }^{\mathrm{TM}}$ Set human IL-6 (cat. no. 555220), IL-8 (cat. no. 555244) and MCP-1 (cat. no. 555179; all BD Biosciences) according to the manufacturer's protocol.

Western blotting. HaCaT cells were treated with S100A8 or S100A9 for $24 \mathrm{~h}$, and the cells were harvested and lysed with 

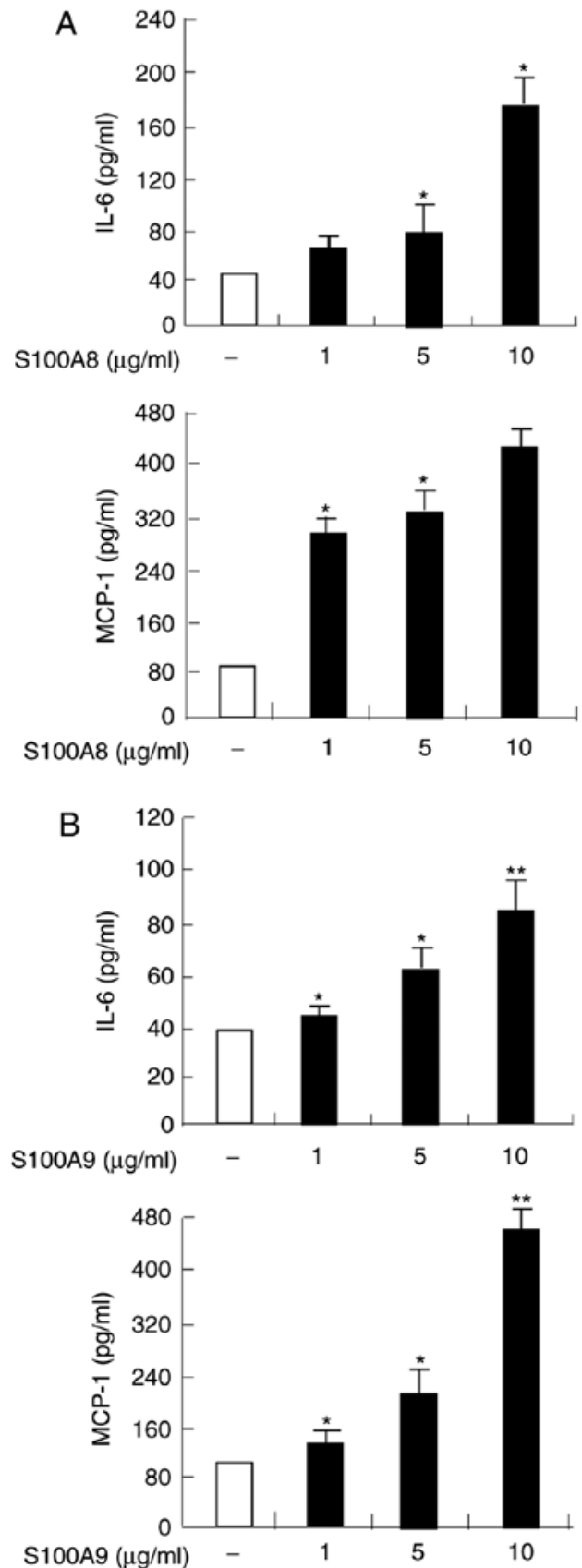
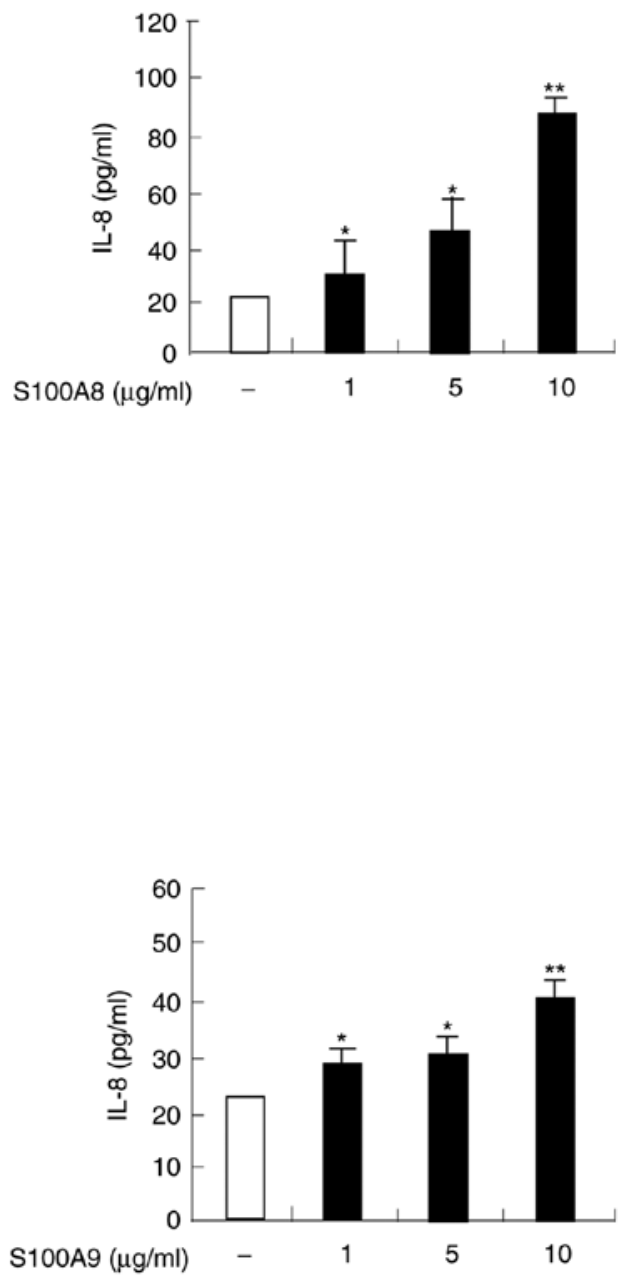

Figure 2. HaCaT cells were treated with the indicated concentrations $(\mu \mathrm{g} / \mathrm{ml})$ of $(\mathrm{A}) \mathrm{S} 100 \mathrm{~A} 8$ or $(\mathrm{B}) \mathrm{S} 100 \mathrm{~A} 9$ for $48 \mathrm{~h}$ and IL-6, IL-8, and MCP-1 were released in a dose-dependent manner, as measured by ELISA. Data are expressed as the mean \pm standard deviation. ${ }^{*} \mathrm{P}<0.05$ and ${ }^{* *} \mathrm{P}<0.01$ vs. the control. S100, calcium binding protein; IL, interleukin; MCP, monocyte chemoattractant protein.

lysis buffer (TransLab). The homogenate was centrifuged at $12,000 \mathrm{x}$ g for $15 \mathrm{~min}$ at $4^{\circ} \mathrm{C}$, and the supernatant was collected as total lysate. Protein concentration of the lysate was measured by a protein assay kit (Thermo Scientific, Inc.). Following separation of the protein samples $(50 \mathrm{mg} /$ lane) by $10 \%$ SDS-PAGE, the transferred nitrocellulose membranes were incubated with primary $(1: 1,000)$ and secondary antibodies as described in the reagents section $(1: 3,000)$ for $1 \mathrm{~h}$ at room temperature, and developed by using an enhanced chemiluminescence detection system (Amersham; GE Healthcare, Chicago, IL, USA). The same blot was stripped and re-probed with anti-ERK2 or anti- $\beta$-actin antibodies as described in the reagents section used as an internal control.
$N F-\kappa B$ p 65 transcription factor assay. The DNA-binding activity of NF- $\kappa \mathrm{B}$ was assessed by using EZ-Detect ${ }^{\mathrm{TM}}$ transcription factor kits for NF- $\kappa \mathrm{B}$ p65 (Pierce; Thermo Fisher Scientific, Inc.) according to the manufacturer's protocol. DNA-binding specificity was evaluated by using wild type (5'-CACAGTTGAGGGGACTTTCCCAGGC-3') or mutant NF- $\kappa$ B oligonucleotides (5'-CACAGTTGAGGCCACTTT CCCAGGC-3'). Chemiluminescent detection was performed using a luminometer (Thermo Fisher Scientific, Inc.).

Statistical analysis. All data $(\mathrm{n}=38)$ are presented as the mean \pm standard deviation. Data were analyzed by using a paired Student's t-test for two-group comparisons and a one-way 
A
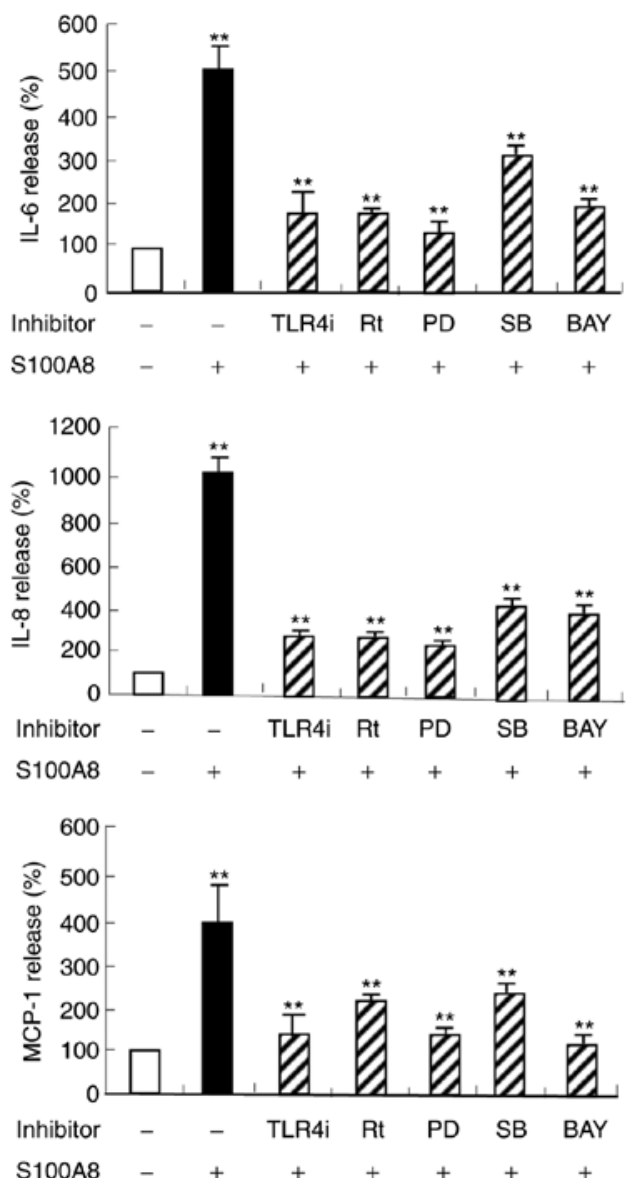
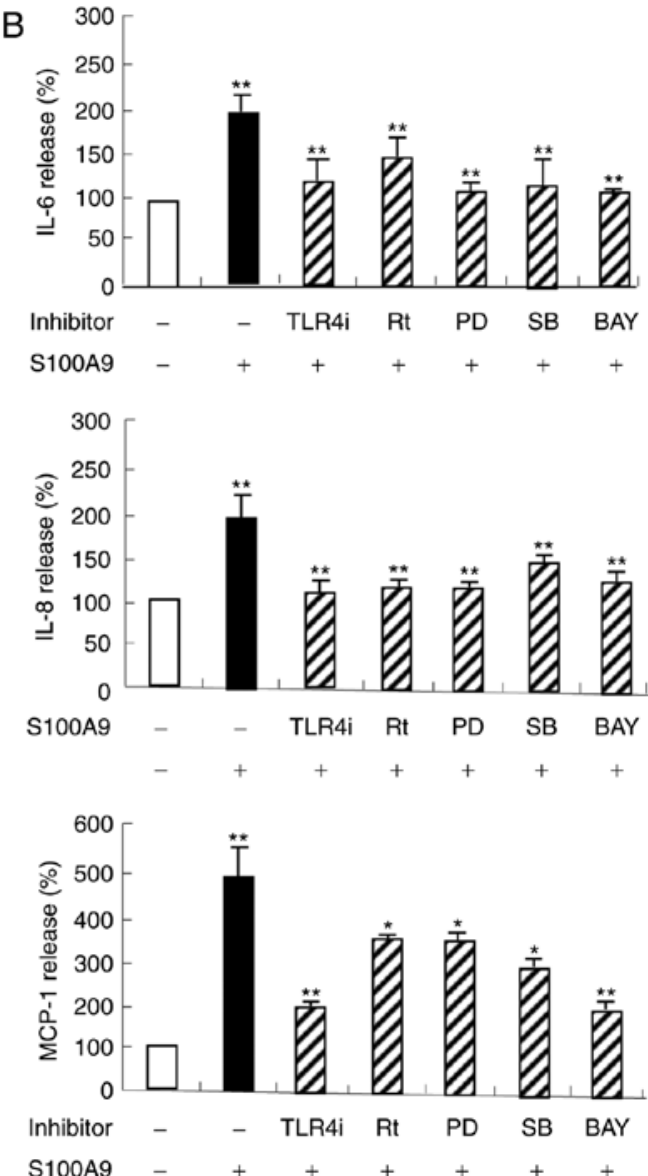

Figure 3. HaCaT cells were pretreated for $1 \mathrm{~h}$ with and without $5 \mu \mathrm{M}$ TLR4i, $5 \mu \mathrm{M}$ Rt, $10 \mu \mathrm{M}$ PD, $10 \mu \mathrm{M}$ SB or $2 \mu \mathrm{M}$ BAY, followed by incubation with (A) S100A8 or (B) S100A9 for $48 \mathrm{~h}$. Data are expressed as the mean \pm standard deviation. ${ }^{*} \mathrm{P}<0.05$ and ${ }^{* *} \mathrm{P}<0.01$ vs. the control. IL, interleukin; S100, calcium binding protein; TLR, toll-like receptor; TLR4i, CLI-095; Rt, rottlerin; PD, PD98059; SB, p38 mitogen-activated protein kinase inhibitor; BAY, BAY-11-7085; $\mathrm{MCP}$, monocyte chemoattractant protein.

analysis of variance with Tukey's post hoc tests for comparisons of more than two groups. Analyses were performed using the SPSS statistical software package, version 10.0 (SPSS, Inc., Chicago, IL, USA). $\mathrm{P}<0.05$ was considered to indicate a statistically significant difference.

\section{Results}

S100A8 and S100A9 induce expression of IL-6, IL-8, and MCP-1 in HaCaT cells, which is associated with TLR4, PKCD, $E R K, p 38 M A P K$ and $N F-\kappa B$ signaling pathways. The protein expression levels of IL-6, IL-8 and MCP-1 were significantly increased in a time and dose-dependent manner following S100A8 or S100A9 treatment, in HaCaT cells (Figs. 1 and 2). To evaluate the signaling mechanism(s) induced by S100A8 and S100A9 treatment, alteration of the cytokine expression was evaluated by pretreatment with protein-specific inhibitors prior to S100A8 and S100A9 stimulation. As demonstrated in Fig. 3, the expression levels of IL-6, IL-8, and MCP-1 increased by S100A8 or S100A9 treatment, were significantly reduced by specific inhibitors, including TLR4i, rottlerin, PD98059, SB203580 and BAY-11-7085. These results confirmed that TLR4, PKCס, ERK, p38 MAPK and NF- $\kappa$ B signaling pathways are involved in S100A8 or S100A9-induced secretion of IL-6, IL-8 and MCP-1.
S100A8 and S100A9 induce activation of ERK, p38 MAPK and $N F-\kappa B$ signaling pathways. Since the signaling inhibitors blocked cytokine release induced by S100A8 and S100A9, whether S100A8 and S100A9 induce activation of MAPK and $\mathrm{NF}-\kappa \mathrm{B}$ signaling pathways was examined. Following stimulation with S100A8 and S100A9, phosphorylation of ERK and p38 MAPK was induced, reaching maximal phosphorylation levels at $1 \mathrm{~h}$ (Fig. 4A). Additionally, ERK and p38 MAPK activation induced by S100A8 and S100A9 was blocked by TLR4i and rottlerin (Fig. 4B). These results indicated that S100A8 and S100A9 activate ERK and p38 MAPK signaling pathways via TLR4 and rottlerin. As shown in Fig. 5, both S100A8 and S100A9 NF- $\kappa$ B activity in a time-dependent manner, and this activation was suppressed by TLR4i, rottlerin, PD98059 and SB202190. In addition, TLR4 expression was upregulated by S100A8 and S100A9 (Fig. 6). These results indicated that

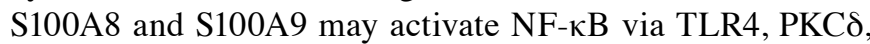
ERK and p38 MAPK signaling pathways.

Filaggrin and loricrin expression levels are decreased by S100A8 and S100A9. As skin barrier proteins are important in the pathogenesis of AD, whether S100A8 and S100A9 alter the expression of filaggrin, loricrin and involucrin was examined. The expression levels of filaggrin and loricrin were decreased following stimulation with S100A8 or S100A9; whereas 
A
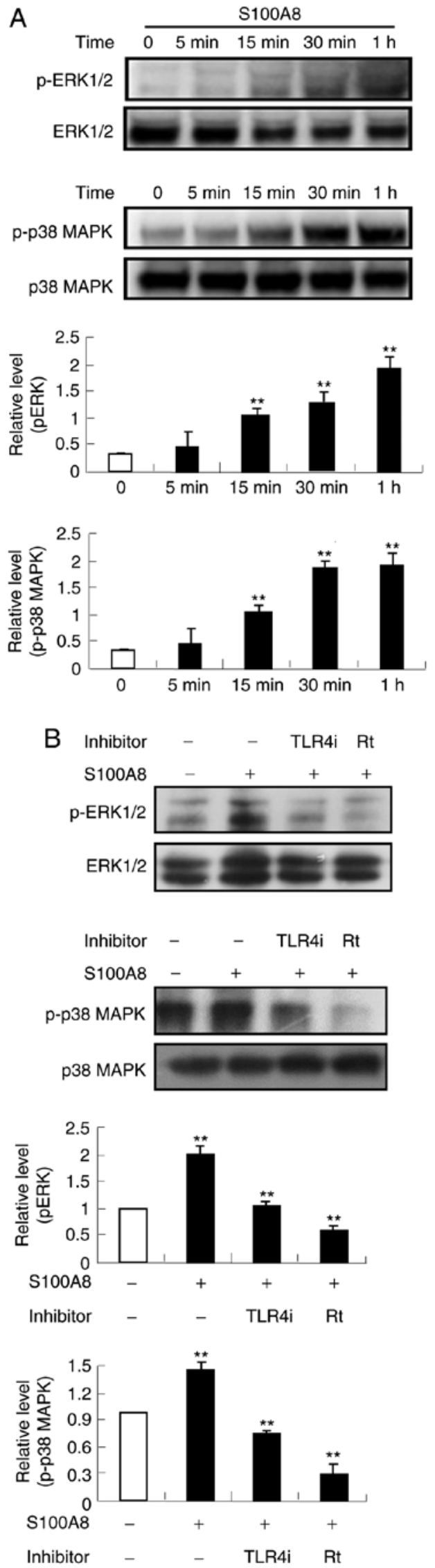
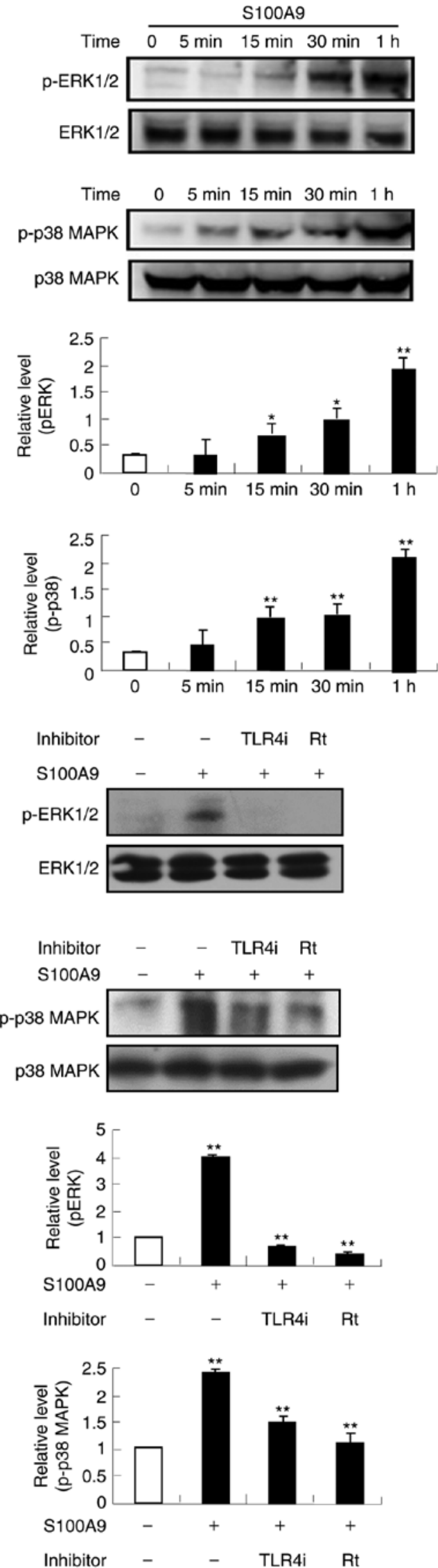

Figure 4. S100A8 and S100A9 induced activation of ERK and p38 MAPK. (A) HaCaT cells were incubated with S100A8 and S100A9 (10 $\mu$ g/ml) for the indicated times and phosphorylation of ERK and p38 MAPK in the lysates was measured by western blotting. (B) HaCaT cells were pretreated for $1 \mathrm{~h}$ with and with $5 \mu \mathrm{M}$ TLR4i or $5 \mu \mathrm{M}$ Rt, followed by incubation with S100A8 and S100A9 (10 $\mu \mathrm{g} / \mathrm{ml})$ and p-ERK and p-p38 MAPK in the lysates were measured by western blotting. Data are expressed as the mean \pm standard deviation. ${ }^{*} \mathrm{P}<0.05$ and ${ }^{* *} \mathrm{P}<0.01 \mathrm{~S} 100 \mathrm{~A} 8 / \mathrm{A} 9$-treated group vs. the control and inhibitor-treated group vs. S100A8/A9-treated group. S100, calcium binding protein; p-, phosphor-; ERK, extracellular signal-regulated kinase; MAPK, mitogen-activated protein kinase; TLR, toll-like receptor; TLR4i, CLI-095; Rt, rottlerin. 
A

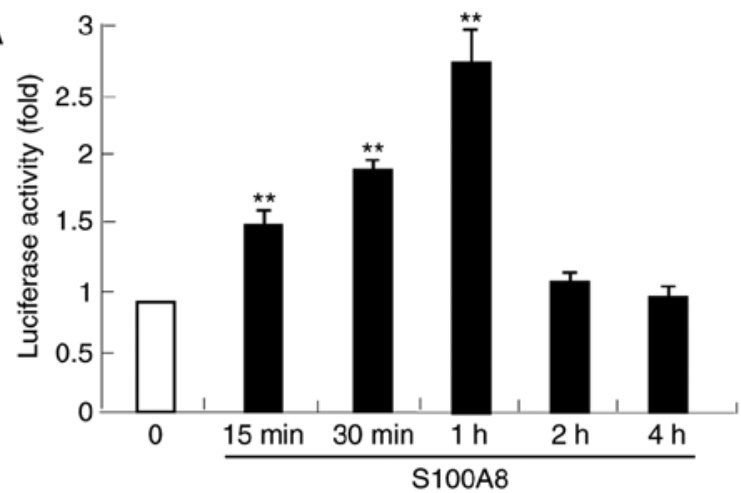

$\mathrm{B}$

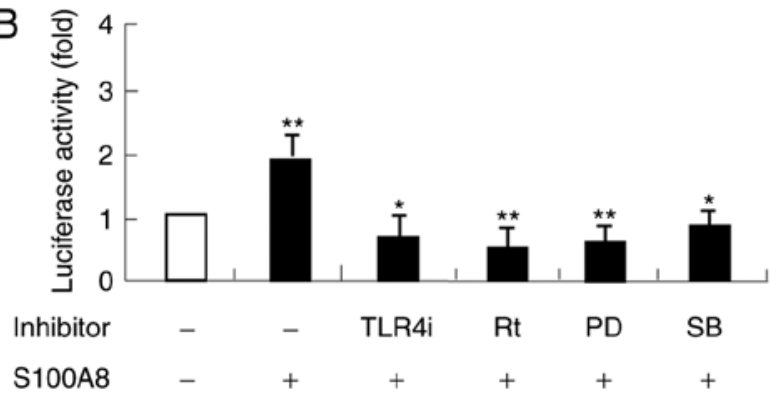

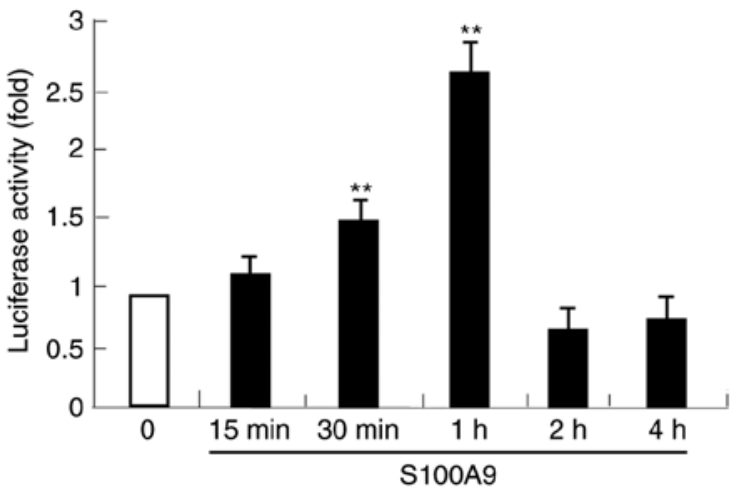

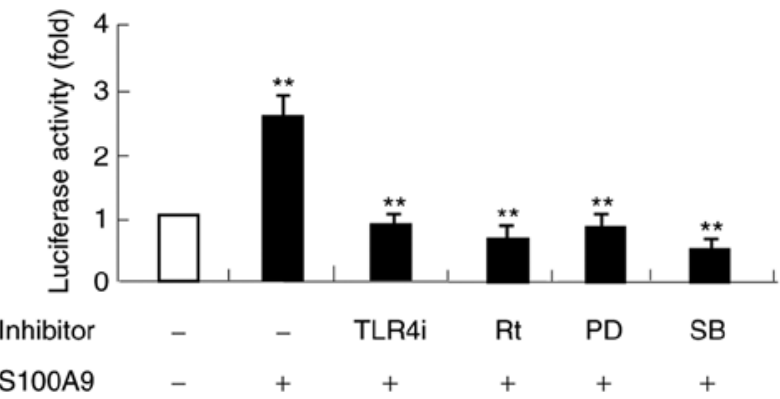

Figure 5. S100A8 and S100A9 induced NF- $\kappa$ B activation. (A) HaCaT cells were incubated with S100A8 and S100A9 (10 $\mu \mathrm{g} / \mathrm{ml})$ for the indicated times. (B) $\mathrm{HaCaT}$ cells were pretreated for $1 \mathrm{~h}$ with and with $5 \mu \mathrm{M}$ TLR4i, $5 \mu \mathrm{M}$ Rt, $10 \mu \mathrm{M}$ PD or $10 \mu \mathrm{M}$ SB, followed by incubation with S100A8 or S100A9 $(10 \mu \mathrm{g} / \mathrm{ml})$ for $1 \mathrm{~h}$ and $\mathrm{NF}-\kappa \mathrm{B}$ in the lysates was measured by luciferase activity assay. Data are expressed as the mean \pm standard deviation. ${ }^{*} \mathrm{P}<0.05$ and ${ }^{* *} \mathrm{P}<0.01 \mathrm{~S} 100 \mathrm{~A} 8 / \mathrm{A} 9$-treated group vs. the control and inhibitor-treated group vs. S100A8/A9-treated group. NF- $\mathrm{B}$, nuclear factor- $\kappa \mathrm{B}$; S100, calcium binding protein; TLR, toll-like receptor; TLR4i, CLI-095; Rt, rottlerin; PD, PD98059; SB, p38 mitogen-activated protein kinase inhibitor.
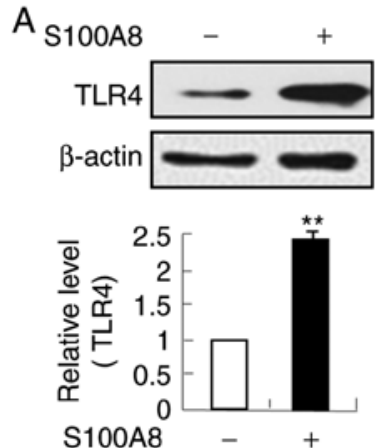
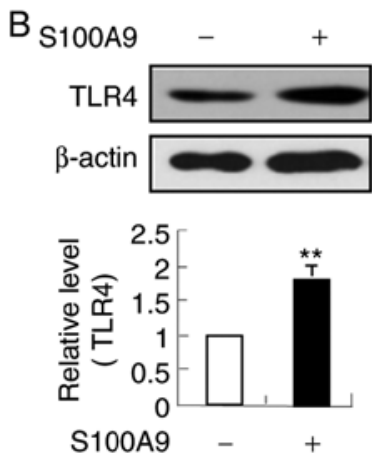

Figure 6. HaCaT cells were treated with (A) S100A8 or (B) S100A9 $(10 \mu \mathrm{g} / \mathrm{ml})$ for $24 \mathrm{~h}$ and TLR4 expression was increased as assessed by western blotting. Data are expressed as the mean \pm standard deviation. ${ }^{* *} \mathrm{P}<0.01$ vs. the control. S100, calcium binding protein; TLR4, toll-like receptor 4 .

involucrin expression was not altered (Fig. 7). These results indicated that S100A8 and S100A9, in addition to regulating cytokine production, may also regulate skin barrier proteins expression.

\section{Discussion}

The S100 proteins have calcium-binding capacity and can induce a variety of inflammatory responses. S100A8 and S100A9 are produced by neutrophils, monocytes, macrophages, and keratinocytes and their expression levels are increased under inflammatory conditions (4). IL-1 $\alpha$ is produced by epithelial cells and acts autonomously on those cells to induce the expression of S100A9 and cellular differentiation (11). Decreased hydration induces the expression of S100A8 and S100A9, resulting in an increase in hypertrophic scarring (12). In addition, S100A8 and S100A9 levels are increased in lesional skin of patients with $\operatorname{AD}(13,14)$. In the present study, it was examined whether S100A8 and S100A9, which are involved in AD, alter the expression levels of cytokines and skin barrier proteins. S100A8 and S100A9 increased the expression of IL-6, IL-8, and MCP-1 in human keratinocytes. MCP-1 is a member of the $\mathrm{C}-\mathrm{C}$ chemokine family and a potent chemotactic factor in monocytes that can modulate the migration and invasion of macrophages, memory $\mathrm{T}$ cells and natural killer cells (8). Additionally, MCP-1 is implicated in a variety of inflammatory diseases, including asthma, rheumatoid arthritis and chronic idiopathic urticarial (8). Furthermore, increased expression of MCP-1 contributes to the proinflammatory environment in $\mathrm{AD}(8,15)$. IL-6 serves essential roles in the transition from acute to chronic inflammation. IL-8 secreted by macrophages is associated with inflammatory conditions. The complex interaction of these cytokines with chemokines may evoke AD pathogenesis (15). In addition, immunological reactions induced by $\mathrm{S} 100$ proteins include intracellular and extracellular signaling. The human keratinocytic $\mathrm{HaCaT}$ cell has low basal endogenous and exogeneous expression of S100A8 and S100A9 (16). Although it is expected that inflammatory cytokines induce intracellular expression or secretion of S100A8 and S100A9, the exact stimuli are still unknown and needs to be investigated further.

Defects in skin barrier function are an essential feature of the development of $\mathrm{AD}$ (17). Although filaggrin, loricrin, and involucrin are three key proteins in skin barrier 

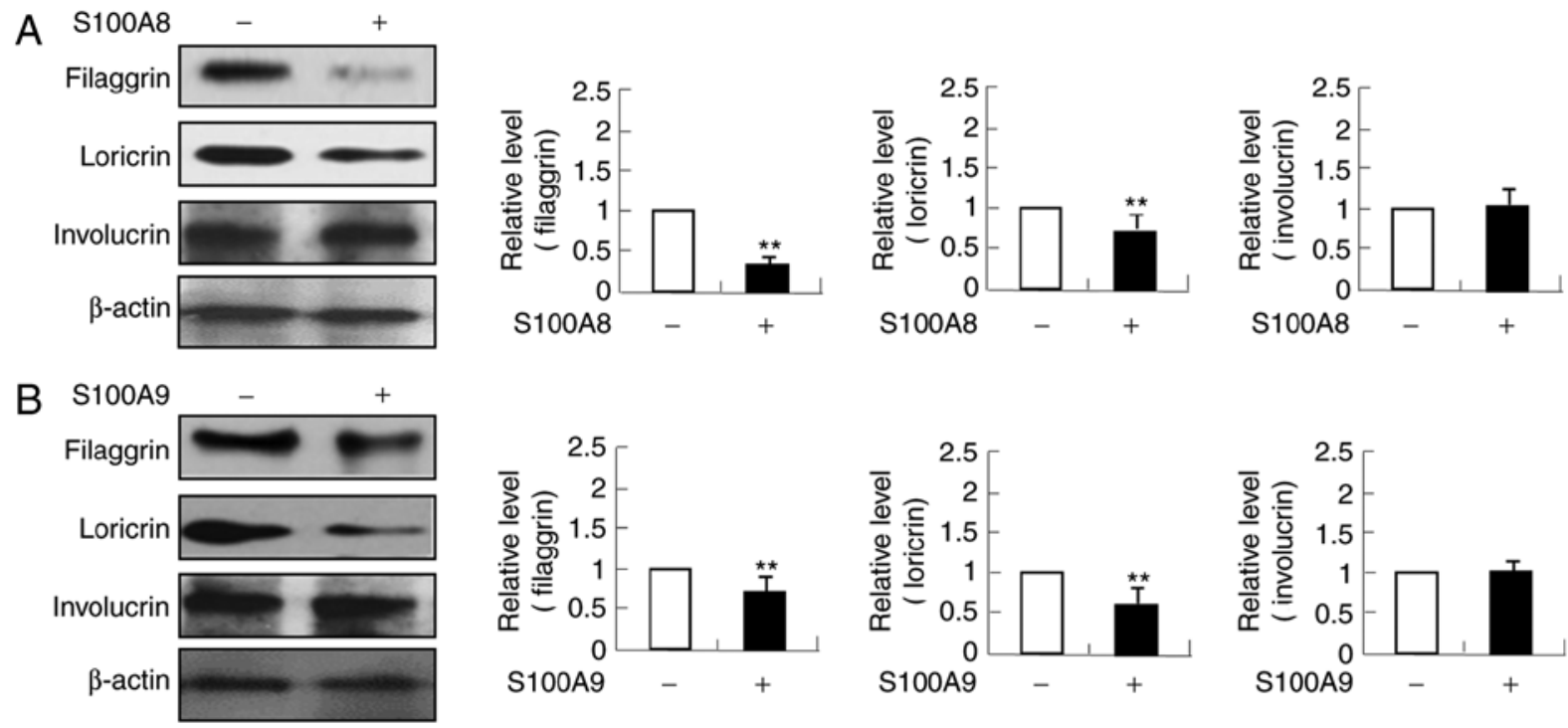

Figure 7. HaCaT cells were treated with (A) S100A8 or (B) S100A9 $(10 \mu \mathrm{g} / \mathrm{ml})$ for $24 \mathrm{~h}$ and filaggrin and loricrin expression levels were decreased as assessed by western blotting. Data are expressed as the mean \pm standard deviation. ${ }^{* *} \mathrm{P}<0.01 \mathrm{vs}$. the control. S100, calcium binding protein.

functions, S100A8 and S100A9 treatment was effective only on the expressions of filaggrin and loricrin with no effect on involucrin expression. These results indicated that S100A8 and S100A9 may have specific inhibitory effects on skin barrier proteins. IL-6 is negatively associated with filaggrin expression, and decreased expression of filaggrin elicits expression of IL-8 and MCP-1 $(18,19)$. Since skin barrier proteins are associated with cytokine secretion, there may be several mechanisms involved in the increase of cytokine secretion and the decrease of filaggrin and loricrin expressions induced by S100A8 and S100A9. Further studies are required to investigate the S100A8- and S100A9-associated mechanisms affecting the expression and function of skin barrier proteins, such as filaggrin and loricrin, and cytokine release.

MAPK is a typical signaling transduction pathway that transduces extracellular stimulation from the cell membrane to the intracellular nucleus (20). MAPK, which is activated by receptors that bind with growth hormones, cytokines and stressors, is involved in a variety of cellular functions, including cell proliferation, differentiation, and apoptosis (21). In the current study, S100A8 and S100A9 induced activation of ERK and p38 MAPK. Both ERK (ERK1/2) and p38 MAPK have important roles in cytokine secretion and allergic diseases, including AD $(21,22)$. c-Jun $\mathrm{N}$-terminal kinase (JNK) is an important MAPK associated with filaggrin expression (17). Further studies are required to investigate the association between the alteration of skin barrier proteins and JNK activation. In addition, the present results demonstrated that TLR4 is elevated following S100A8 and S100A9 treatment. It can be hypothesized that the increased TLR4 expression levels due to S100A8 and S100A9 treatment enhance cytokine secretion induced by S100A8 and S100A9 via TLR4; this positive feedback loop may result in alleviation of $\mathrm{AD}$.

In summary, S100A8 and S100A9 promote cytokine production, which is critical in the inflammation response, and decrease filaggrin and loricrin expression levels. These observations indicate that S100A8 and S100A9 may be important molecules in the pathogenesis and progression of $\mathrm{AD}$.

\section{Acknowledgements}

Not applicable

\section{Funding}

This study was supported by the BK21 plus program through the National Research Foundation (NRF) funded by the Ministry of Education of Korea and by Sysmex Korea Inc. (grant no. 19-001).

\section{Availability of data and materials}

The datasets used and/or analyzed during the current study are available from the corresponding author on reasonable request.

\section{Authors' contributions}

MJK wrote manuscript, performed the experiments, and analyzed the data. MAI and JSL performed the experiments and analyzed the data. JYM, DHK, and AG interpreted the data. ISK conceived the study, designed the experiments, and reviewed the paper.

\section{Ethics approval and consent to participate}

Not applicable.

\section{Patient consent for publication}

Not applicable.

\section{Competing interests}

The authors declare that they have no competing interests. 


\section{References}

1. Spergel JM and Paller AS: Atopic dermatitis and the atopic march. J Allergy Clin Immunol 112 (6 Suppl): S118-S127, 2003.

2. Bieber T: Atopic dermatitis. N Engl J Med 358: 1483-1494, 2008

3. Kim EH, Lee JS, Lee NR, Baek SY, Kim EJ, Lee SJ and Kim IS Regulation of constitutive neutrophil apoptosis due to house dust mite allergen in normal and allergic rhinitis subjects. PLoS One 9: e105814, 2014.

4. Goyette J and Geczy CL: Inflammation-associated S100 proteins new mechanisms that regulate function. Amino Acids 41: 821-842, 2011.

5. Kim IS and Lee JS: Anti-apoptotic Effects of house dust mite S100A8 and S100A9 on spontaneous apoptosis of neutrophils in coculture with immune cells and in the presence of $\mathrm{T}$ helper cytokines. Biomed Sci Lett 21: 122-125, 2015.

6. Nacken W, Roth J, Sorg C and Kerkhoff C: S100A8/S100A9: Myeloid representatives of the S100 protein family as prominent players in innate immunity. Microsc Res Tech 60: 569-580, 2003.

7. Foell D and Roth J: Proinflammatory S100 proteins in arthritis and autoimmune disease. Arthritis Rheum 50: 3762-3771, 2004.

8. Kim IS, Kim DH, Yun CY and Lee JS: A (S)-(+)-decursin derivative, (S)-(+)-3-(3,4-dihydroxy-phenyl)-acrylic acid 2,2-dimethy 1-8-oxo-3,4-dihydro-2H,8H-pyrano[3,2-g]-chromen-3-yl-ester, attenuates the development of atopic dermatitis-like lesions in NC/Nga mice. Mol Biol Rep 40: 2541-2548, 2013.

9. Kim IS, Kim MJ, Shin DH, Son KH, Park HY and Lee JS: Arazyme inhibits cytokine expression and upregulates skin barrier protein expression. Mol Med Rep 8: 551-556, 2013.

10. Kim DH, Choi E, Lee JS, Lee NR, Baek SY, Gu A, Kim DH and Kim IS: House dust mite allergen regulates constitutive apoptosis of normal and asthmatic neutrophils via Toll-like receptor 4. PLoS One 10: e0125983, 2015.

11. Bando M,Zou X, Hiroshima Y, Kataoka M, Ross KF, Shinohara Y, Nagata T, Herzberg MC and Kido J: Mechanism of interleukin-1 $\alpha$ transcriptional regulation of S100A9 in a human epidermal keratinocyte cell line. Biochim Biophys Acta 1829: 954-962, 2013.

12. Zhong A, Xu W, Zhao J, Xie P, Jia S, Sun J, Galiano RD, Mustoe TA and Hong SJ: S100A8 and S100A9 are induced by decreased hydration in the epidermis and promote fibroblast activation and fibrosis in the dermis. Am J Pathol 186: 109-122, 2016
13. Jin S, Park CO, Shin JU, Noh JY, Lee YS, Lee NR, Kim HR, Noh S, Lee Y, Lee JH and Lee KH: DAMP molecules S100A9 and S100A8 activated by IL-17A and house-dust mites are increased in atopic dermatitis. Exp Dermatol 23: 938-941, 2014.

14. Sakaguchi M, Yamamoto M, Miyai M, Maeda T, Hiruma J, Murata H, Kinoshita R, Winarsa Ruma IM, Putranto EW, Inoue Y, et al: Identification of an S100A8 receptor neuroplastin- $\beta$ and its heterodimer formation with EMMPRIN. J Invest Dermatol 136: 2240-2250, 2016.

15. Kim IS, Song GY, Kim DH, Cho SH, Yun CY and Lee JS: Effect of (E)-2-(3,4-dimethoxy phenyl)-4-oxo-4H-chromen-7-yl-3(3,4-dimethoxyphenyl) acrylate on the development of atopic dermatitis-like lesions. Life Sci 91: 338-344, 2012.

16. Benedyk M, Sopalla C, Nacken W, Bode G, Melkonyan H, Banfi B and Kerkhoff C: HaCaT keratinocytes overexpressing the S100 proteins S100A8 and S100A9 show increased NADPH oxidase and NF-kappaB activities. J Invest Dermatol 127: 2001-2011, 2007.

17. Cha KJ, Im MA, Gu A, Kim DH, Lee D, Lee JS, Lee JS and Kim IS: Inhibitory effect of Patrinia scabiosifolia Link on the development of atopic dermatitis-like lesions in human keratinocytes and NC/Nga mice. J Ethnopharmacol 206: 135-143, 2017.

18. Sakai T, Hatano Y, Zhang W, Fujiwara S and Nishiyori R: Knockdown of either filaggrin or loricrin increases the productions of interleukin (IL)-1 $\alpha$, IL-8, IL-18 and granulocyte macrophage colony-stimulating factor in stratified human keratinocytes. J Dermatol Sci 80: 158-160, 2015.

19. Ilves T, Tiitu V, Suttle MM, Saarinen JV and Harvima IT: Epidermal expression of filaggrin/profilaggrin is decreased in atopic dermatitis: Reverse association with mast cell tryptase and IL-6 but not with clinical severity. Dermatitis 26: 260-267, 2015.

20. Chang L and Karin M: Mammalian MAP Kinase signaling cascades. Nature 410: 33-40, 2011.

21. Park JH, Kim MS, Jeong GS and Yoon J: Xanthii fructus extract inhibits TNF- $\alpha / \mathrm{IFN}-\gamma$-induced Th2-chemokines production via blockade of NF-кB, STAT1 and p38-MAPK activation in human epidermal keratinocytes. J Ethnopharmacol 171: 85-93, 2015.

22. Lee NR, Park BS, Kim SY, Gu A, Kim DH, Lee JS and Kim IS: Cytokine secreted by S100A9 via TLR4 in monocytes delays neutrophil apoptosis by inhibition of caspase 9/3 pathway. Cytokine 86: 53-63, 2016. 